\title{
Crepuscular foraging by a pursuit-diving seabird: tactics of common murres in response to the diel vertical migration of capelin
}

\author{
P. M. Regular ${ }^{1, *}$, G. K. Davoren ${ }^{2}$, A. Hedd ${ }^{1}$, W. A. Montevecchi ${ }^{1}$ \\ ${ }^{1}$ Cognitive and Behavioural Ecology Program, Memorial University, St. John's, Newfoundland and Labrador A1B 3X9, \\ Canada \\ ${ }^{2}$ Department of Biological Sciences, University of Manitoba, Winnipeg, Manitoba R3T 2N2, Canada
}

\begin{abstract}
The spatial and temporal distribution of prey directly influences the foraging and feeding behaviour of predators. To investigate predator-prey interactions through the diel cycle, we examined continuous records of diving activity by a pursuit-diving seabird, the common murre Uria aalge, in conjunction with fine-scale data on the vertical distribution of their main prey, capelin Mallotus villosus, off the northeast Newfoundland coast, Canada. Diurnal patterns in the diving activities of murres closely reflected changes in the vertical distribution and movements of capelin. During daylight hours, $43 \%$ of murre dives were deep ( $\geq 50 \mathrm{~m}$ ), bringing murres into sub- $0^{\circ} \mathrm{C}$ water in the Cold Intermediate Layer ( $\mathrm{CIL} ; \sim 40$ to $240 \mathrm{~m}$ ), when $82 \%$ of capelin biomass was located within or below the CIL. At night, murres concentrated diving activity at shallower depths $(94 \%$ of dives were $<50 \mathrm{~m}$ ) when $86 \%$ of capelin biomass was in the upper water column. Capelin migrated through the water column during twilight periods, moving up at dusk and down at dawn. In response, murres' diving frequency increased and diving depths were graduated, becoming shallower through dusk and deeper through dawn. Crepuscular habits indicate that capelin are more accessible during twilight periods. In summary, though murres are constrained by commuting costs, they show exceptional behavioural flexibility in their efforts to access capelin throughout their diel vertical migration (DVM). The various trade-offs involved in such predator-prey interactions are discussed, as are the ecological consequences of the DVM pattern across trophic levels.
\end{abstract}

KEY WORDS: Crepuscular foraging $\cdot$ Diel vertical migration $\cdot$ DVM $\cdot$ Common murre $\cdot$ Uria aalge Capelin $\cdot$ Mallotus villosus $\cdot$ Prey distribution $\cdot$ Diving behaviour

\section{INTRODUCTION}

The phenomenon of diel vertical migration (DVM) by zooplankton has broad-scale ecological consequences, directly influencing the foraging behaviour of predators at higher trophic levels (Hays 2003). In general, the pattern involves the movement of zooplankton from deep, dark water depths during the day to shallow depths at night. Migrating zooplankton may experience reduced predation by using dark waters as a refuge from visually orienting predators (predator evasion hypothesis: Zaret \& Suffern 1976). Driven by co-evolution, some predators adapt behaviour to exploit vertically migrating prey.

Diel behavioural adjustments have been observed in a wide range of taxa, including invertebrates (Tarling et al. 2001), fish (Shepard et al. 2006), seals (Croxall et al. 1985) and seabirds (Wilson et al. 1993). Airbreathing marine predators that exploit diel prey are faced with added underwater commuting costs, as they must always return to the surface. This constrains maximum foraging depths and the time they can spend foraging. Furthermore, they risk losing contact with prey between dives. These costs are lower at night when 
vertically migrating prey are near the surface, but this does not necessarily lead to increased foraging efficiency since darkness likely makes it more difficult to locate, capture or handle prey (Wilson et al. 1993, Bost et al. 2002, Hedd et al. 2009). Although previous studies document diel behavioural patterns of predators and explain them in relation to general patterns of prey and light availability, we know of no attempt to assess fine-scale associations of the timing of vertical movements of predators and prey. Likewise, few studies address ecological consequences across multiple trophic levels (Levy 1990, Hays 2003).

Among the seabird species that fly and dive, common murres Uria aalge dive the deepest to pursue and capture their prey (Piatt \& Nettleship 1985, Burger 1991). In the northwest Atlantic, breeding common murres provision themselves and their chicks primarily on capelin Mallotus villosus (Montevecchi 2000, Davoren \& Montevecchi 2003). Capelin lie at the core of the northwest Atlantic food web, as they are major consumers of zooplankton and are focal forage fish (Lavigne 1996). They adjust their vertical distribution in a DVM pattern to track that of zooplankton prey and minimize predation by northern cod Gadus morhua, their primary predator (Mowbray 2002). Breeding murres are constrained by underwater commuting costs and their physiological capabilities. Their energetic costs are the highest during the land-based chick-rearing period as parental murres have to forage and provision their offspring from a fixed colony location (central-place foraging; Orians \& Pearson 1979). These extreme conditions often push parental seabirds to their behavioural and physiological limits (e.g. Elliott et al. 2008).

As parents provision both themselves and their chicks with capelin, we hypothesized that their diving activities will track the movements of capelin to the extent that their physiology will allow. In other words, we expected that changes in the vertical distribution of capelin would explain patterns in the diving behaviour of parental murres. Furthermore, because energetic demands are high, we also expected that these pursuit-diving seabirds would exhibit flexible foraging tactics. In particular, we predicted that murres would minimize costs by concentrating foraging activities during periods when their ability to capture prey is the highest. It is during these times that we also expected the birds to focus chick-provisioning efforts. We assess these diurnal associations by comparing hydroacoustic survey data of capelin and bird-borne device data from common murres collected in the waters surrounding the seabird breeding colony on Funk Island, Newfoundland, in the northwest Atlantic Ocean. The broad-scale vertical movements of capelin (migrate $<300 \mathrm{~m}_{i}$ Davoren et al. 2007) and diving capabilities of murres (dive $<177 \mathrm{~m}$; present study) make these species excellent candidates to evaluate these associations.

\section{MATERIALS AND METHODS}

Study site. DVM patterns of capelin were studied during a 4 d survey (10 to 14 August 2005) on the $60 \mathrm{~m}$ Fisheries and Oceans Canada RV 'Wilfred Templeman' (Davoren et al. 2007), in an area containing large concentrations of post-spawning capelin off New-

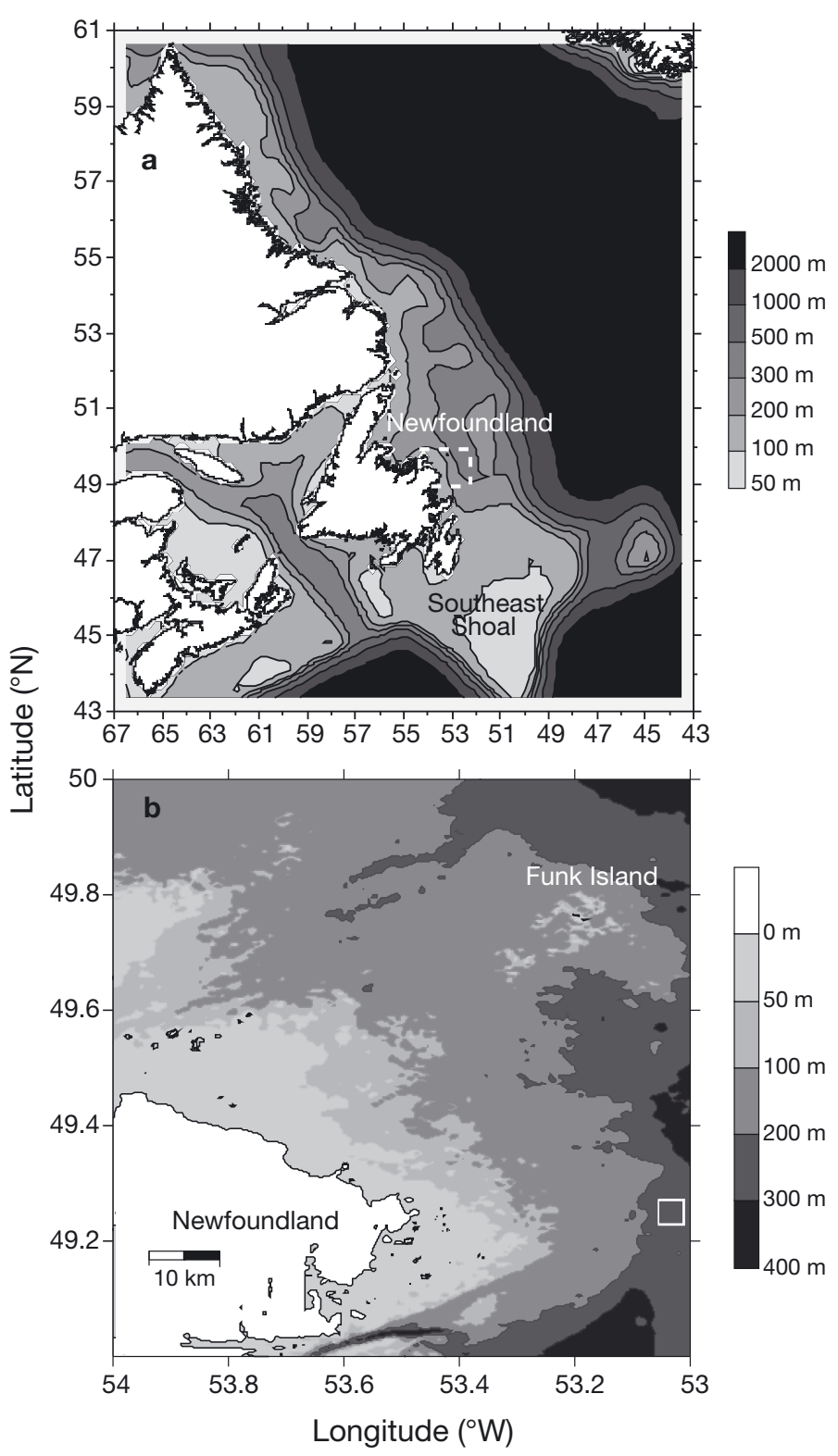

Fig. 1. Location of (a) Newfoundland study area (dashed white square), (b) capelin Mallotus villosus survey area (white square) and Funk Island 
foundland's northeast coast in eastern Canada $\left(49^{\circ} 15^{\prime} \mathrm{N}, 53^{\circ} 02^{\prime} \mathrm{W}\right.$; Fig. 1). The area was within the foraging range of common murres from Funk Island $\left(49^{\circ} 45^{\prime} \mathrm{N}, 53^{\circ} 11^{\prime} \mathrm{W}\right.$; Fig. 1), the site of the species' largest North American colony ( 400000 breeding pairs; Montevecchi \& Tuck 1987, Chardine et al. 2003), at a time when most murres were provisioning chicks with capelin (25 to 30 July 2007 and 23 to 29 July 2008; Davoren \& Montevecchi 2003, Hedd et al. 2009). The waters around Funk Island have a gradually sloping bathymetry, whereby water depth increases with increasing distance from the coast (Fig. 1). Parental murres therefore have access to a range of water depths as they can forage at distances $>80 \mathrm{~km}$ from the colony (Burke \& Montevecchi 2009). The water depth $(\sim 270 \mathrm{~m})$ in the capelin survey area extends beyond the murre's known diving capability $(<177 \mathrm{~m}$; present study). The spatial and temporal mismatch in data collection permits, only indirect comparisons; nevertheless, predator-prey comparisons are informative as the DVM movements of capelin are expected to be conserved. Coarser-scale research conducted during June 2000 demonstrated that shoals of maturing and spent capelin across a range of bathymetries exhibited DVM (Davoren et al. 2006). Thus, with the exception of foraging at shallow inshore spawning sites $(<50 \mathrm{~m}$; Davoren et al. 2006), the murres studied here were likely foraging on capelin shoals that underwent DVM.

Capelin survey design. To quantify the DVM patterns of capelin, we repeatedly collected hydroacoustic data along a star-shaped survey $(\sim 30 \mathrm{~km})$ over the main concentration of capelin such that all $1 \mathrm{~h}$ time blocks over the $24 \mathrm{~h}$ cycle were sampled at least once during the $4 \mathrm{~d}$ study. The same survey was repeated $\sim 18$ times, resulting in $543 \mathrm{~km}$ of acoustic data on the DVM of capelin. Vessel speed (11 to $14 \mathrm{~km} \mathrm{~h}^{-1}$ ) was held constant throughout all surveys. A Simrad EK 500 hydro-acoustic system calibrated with a tungsten carbide standard target was used aboard the RV 'Wilfred Templeman'. This system operated through a hullmounted $38 \mathrm{kHz}$ split-beam transducer. The transducer was at a depth of $4 \mathrm{~m}$ and a beam pattern would not form within a range of $5 \mathrm{~m}$; therefore, acoustic signals were not reliable until $\sim 10 \mathrm{~m}$. The transducer had a 2-way beam angle of $-20.6 \mathrm{~dB}$ and the echo sounder was operated at 1 ping s${ }^{-1}$ over a depth range of 10 to $300 \mathrm{~m}$, a bandwidth of $3.8 \mathrm{kHz}$ and a pulse duration of $1.0 \mathrm{~ms}$. Raw high-resolution acoustic data (volume backscattering coefficients, $s_{\mathrm{v}}, \mathrm{m}^{-1}$ ) were recorded continuously.

Field work on common murres. To study the diving activities of common murres at sea, adults attending chicks were captured using a $6 \mathrm{~m}$ telescopic noose pole and were equipped with one of 2 types of temperature-depth recorders (TDRs; Lotek Wireless): (1) LTD
1110 (5 g, $11 \times 32 \mathrm{~mm}$; $128 \mathrm{~Kb}$ memory), or (2) LAT 1500 (3.4 g, $8 \times 35$ mm; $512 \mathrm{~Kb}$ memory). LTD 1110s recorded internal device temperature (resolution: $\pm 0.3^{\circ} \mathrm{C}$ ) and pressure (depth resolution: $\pm 0.49 \mathrm{~m}$ when maximum depth $<125 \mathrm{~m}$, and $\pm 0.98 \mathrm{~m}$ when maximum depth 125 to $250 \mathrm{~m}$ ) every 2 s. LAT 1500 devices recorded internal device temperature (resolution $>0.05^{\circ} \mathrm{C}$ ) and wet dry state every $2 \mathrm{~s}$, and pressure (resolution: $0.05 \%$ ) every $2 \mathrm{~s}$ only when the device was wet and the depth was $>1.5 \mathrm{~m}$. TDRs secured to plastic leg bands (Pro-Touch Engraving) were attached to the left legs of the study birds, and a Canadian Wildlife Service metal band was attached to the right leg. Different birds were captured each year; only 1 bird per pair was tagged, and only 1 device was attached to each bird. TDRs were attached to 14 birds in 2007 (all LTD 1110s) and 15 birds in 2008 ( $\mathrm{n}=6$ LTD 1110s and $\mathrm{n}=9$ LAT 1500s). Birds were recaptured after $\sim 3 \mathrm{~d}$ (range 2 to $7 \mathrm{~d}$ ), the tag was removed and $0.5 \mathrm{ml}$ of blood was collected from the brachial vein to determine sex using W-chromosome analysis (Fridolfsson \& Ellegren 1999). Birds were handled for $\sim 3$ and $\sim 6 \mathrm{~min}$ during logger deployment and recapture, respectively. Most birds returned to the chick and resumed parental behaviour within a few minutes of release after deployment and recapture. In total, 19 ( $\mathrm{n}=9$ in 2007; $\mathrm{n}=10$ in 2008) of 29 devices were recovered, of which 18 ( $\mathrm{n}=8$ in 2007; $\mathrm{n}=10$ in 2008) were successfully downloaded. Of the devices recovered in 2008, 6 were LAT 1500s. Devices not recovered are not expected to remain attached for more than 2 yr. One record in 2007 was from a parent incubating an egg and was excluded from the analysis. Device memory lasts $36 \mathrm{~h}$ for LTD 1110s and $\sim 150 \mathrm{~h}$ for LAT 1500s. Records typically lasted for the duration of the deployment.

Data analysis. All raw hydro-acoustic data files were processed using Echoview 4.0 (Myriax Software). A $S_{\mathrm{V}}$ threshold of $-80 \mathrm{~dB}$ was applied to the raw data prior to integration, and acoustic signals near the bottom that could not be distinguished as biological or due to the ocean floor (dead-zone, side-lobing; Lawson \& Rose 1999) were edited out. The $S_{\mathrm{V}}$ in each file was integrated to determine the average aerial backscattering coefficient $\left(s_{\mathrm{a}}, \mathrm{m}^{2} \mathrm{~m}^{-2}\right)$ for each $100 \mathrm{~m}$ of survey and $10 \mathrm{~m}$ depth intervals (MacLennan et al. 2002). The species composition of acoustic signals was regularly sampled throughout the diel cycle using an International Young Gadoid Pelagic Trawl to conduct mid-water trawls (Davoren et al. 2007). Capelin was the dominant fish species sampled $(94.7 \%$ by mass; G. K. Davoren unpubl. data) and, thus, it was assumed that capelin was the only fish contributing to the acoustic backscatter in the water column. Period by time of day was defined as follows: day was the period between sunrise and sunset (sun above $0^{\circ}$ ), dawn and dusk were when 
the sun is between $0^{\circ}$ and $-12^{\circ}$ (nautical twilight), and night the point when the sun is below $-12^{\circ}$. The mean proportion of $S_{\text {a }}$ due to capelin over the entire finescale survey was then determined for each $10 \mathrm{~m}$ depth interval from 10 to $270 \mathrm{~m} \mathrm{~h}^{-1}$ throughout the diel cycle. On a finer scale, the mean proportion of capelin by $10 \mathrm{~m}$ depth interval was calculated on a 15 min interval through twilight periods. Data are presented as minutes \pm sunrise and sunset to control for the temporal mismatch with the collection of murre diving data. Times range from -120 to 30 min from sunrise and -30 to 120 min from sunset, encompassing the whole of dawn and dusk as well as $\sim 15$ min of day and night for both.

Dive profiles and the timing and maximum depth attained during dives were analyzed using MT-Dive 4.0 (Jensen Software). Terminal dives were defined as the last dive in a foraging trip and were coded manually — it is assumed that chick-feeds are captured during terminal dives as murres are single prey loaders. As the drift in the zero-level of the TDRs used exceeded $\pm 1 \mathrm{~m}$ in some cases, dives were considered submersions $\geq 2 \mathrm{~m}$. Dives were categorized into the 4 periods day, dawn, dusk and night, using the definitions given above. To examine patterns in murre diving activity, we plotted frequency distributions by hour. We tested for a diurnal trend in dive depths by hour by fitting polynomial regression (quadratic). We used regression to test linear trends in diving depths during twilight periods. To control for shifts in sunset and sunrise times between and within years, minutes \pm sunrise ( -120 to $30 \mathrm{~min})$ and sunset ( -30 to $120 \mathrm{~min}$ ) were calculated and used in the twilight models. Patterns in diving activity and depths were compared across years and sexes. To account for individual variation and nested variation across days, we used linear mixed models, fit by restricted maximum likelihood, with band and date as random factors. Mean maximum diving depth values by individual, date, and hour or 15 min twilight interval were used in the models to minimize noise in the data. $F$-tests were used to assess the significance of effects and model fit was assessed using parameter estimate $\pm 95 \%$ upper and lower confidence intervals. Analyses were conducted using $\mathrm{R}$ 2.6.2 (R Development Core Team 2008). For more details on the general diving behaviour of breeding common murres see Hedd et al. (2009).

To compare information for capelin and murres, the proportion of capelin present and the depth of murre dives were separated into shallow $(<50 \mathrm{~m})$ and deep ( $\geq 50 \mathrm{~m}$ ) categories by hour through the diel cycle and by $15 \mathrm{~min}$ intervals through twilight periods. The Labrador Current stratifies Newfoundland waters, creating a Cold Intermediate Layer (CIL) of sub- $0^{\circ} \mathrm{C}$ water from $\sim 40$ to $240 \mathrm{~m}$ (Petrie et al. 1988), so this depth classification acts as a biophysically relevant divide for both capelin (Davoren et al. 2006) and murres (Hedd et al. 2009). This classification facilitates comparisons of broad-scale patterns while avoiding issues arising from different sampling areas; in other words, direct comparisons at finer vertical scales are problematic due to the temporal and spatial mismatch. We also note that murres sometimes forage in shallow inshore waters $(<50 \mathrm{~m})$ on spawning capelin that do not undertake DVM (Davoren et al. 2006). Shallow diving activity could therefore be inflated overall in the dataset because such diving activity cannot be excluded from the analysis as the foraging locations of the murres are unknown.

\section{RESULTS}

\section{Vertical distribution of capelin}

Over the diel light cycle, capelin exhibited typical vertical migratory pattern, spanning water depths from 10 to $270 \mathrm{~m}$. During dark periods, the highest percentage of $s_{a}$ due to capelin $(86 \%)$ was observed in the upper water column (10 to $30 \mathrm{~m}$; Fig. 2a). In contrast, during daylight periods, the highest percentage of capelin biomass $(82 \%)$ was found in water $>180 \mathrm{~m}$ deep, below the CIL (Davoren et al. 2007), and just $18 \%$ remained at 10 to $20 \mathrm{~m}$ depth (Fig. 2a). During their dawn and dusk migrations, capelin traversed the water column over $\sim 30$ min (Fig. 2b,c). While processing hydro-acoustic files, distinct capelin shoals were observed during the day and through twilight migrations; however, they remained as a scattered layer of individuals at night (see Fig. 3 in Davoren et al. 2010).

\section{Diving by murres}

The diving profiles of the murres indicated clear diurnal patterns in the depths attained. Fig. 3 depicts a typical profile, with the bird diving deeper during the day than at night and displaying graduated patterns in its maximum dive depths during twilight periods. Lumping data for all individuals $(\mathrm{n}=17$ individuals, 3439 dives), diving activity occurred through the $24 \mathrm{~h}$ cycle (Fig. 4a) with a diel pattern in maximum diving depth, reaching depths up to $177 \mathrm{~m}$ during the day and $81 \mathrm{~m}$ at night (Fig. 4b). By constructing a global model, including hour, hour ${ }^{2}$, year, and sex as fixed effects, we found no significant differences in this trend between years $\left(F_{1,14}=1.86, \mathrm{p}=0.194\right)$ and sexes $\left(F_{1,14}=0.051\right.$, $\mathrm{p}=0.825)$. Analyzing this trend with year and sex excluded from the model, we found a significant improvement in model fit with inclusion of a quadratic 
term $\left(F_{1,379}=68.59, \mathrm{p}<0.0001\right)$. The best fit quadratic equation, with lower and upper confidence intervals of $\beta$ (slope) estimates in parentheses, is: mean maximum dive depth $=21.5(12.3,30.8)+5.80(4.31,7.29) t-0.260$ $(-0.322,-0.198) t^{2} ; t$ is time. This model indicates that there is a significant quadratic trend in the diving depths reached by the murres across the $24 \mathrm{~h}$ period (Fig. 4b). For the finer-scale analysis, we again constructed a global model and found there were no differences in the trend across years (dawn: $F_{1,9}=0.149$,
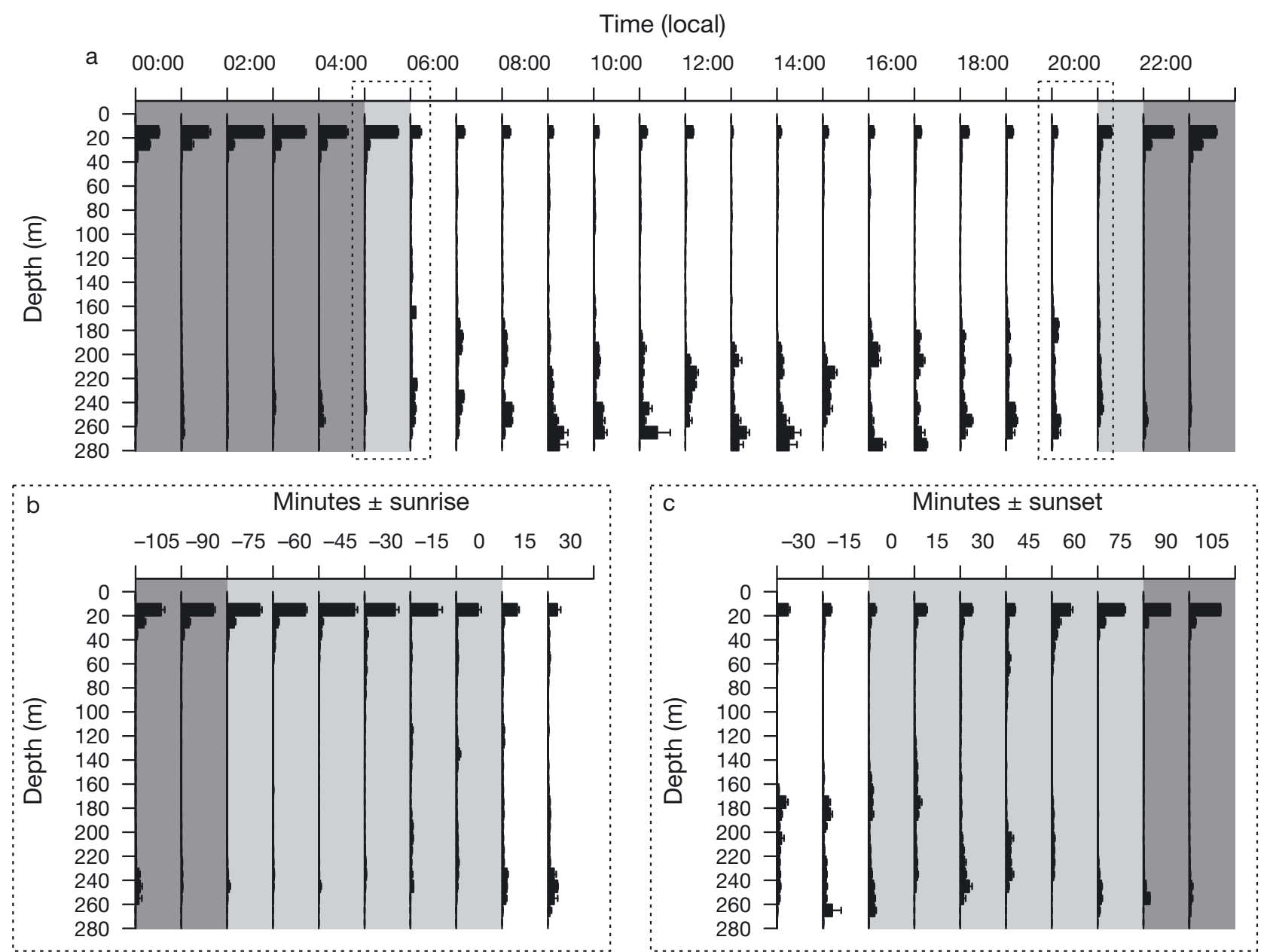

Fig. 2. Mallotus villosus. Vertical distribution of percent capelin biomass \pm SE (scale 0 to $100 \%$ ) (a) by hour, and at 15 min intervals through (b) dawn and (c) dusk. Shading: twilight (light grey), night time (dark grey), and daytime (unshaded)

Time (local)

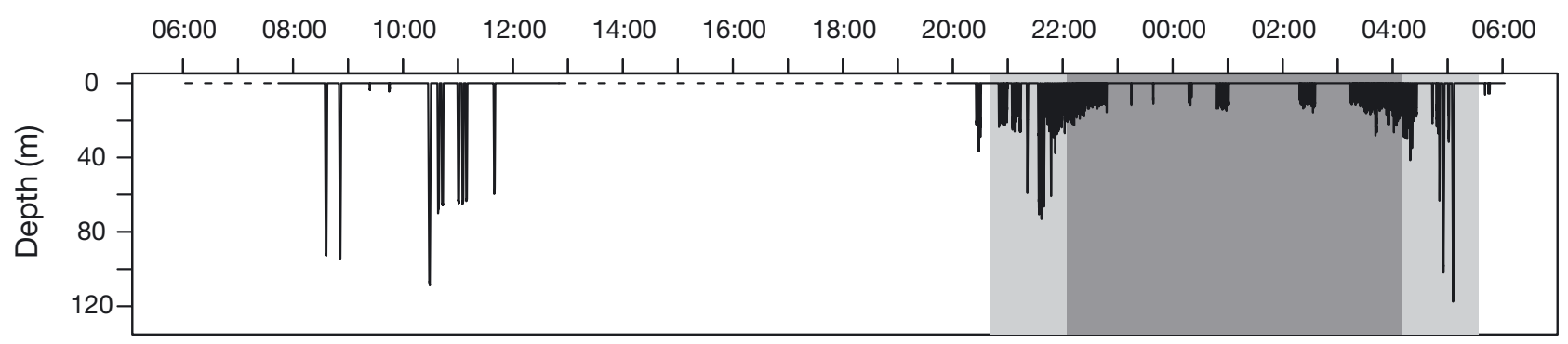

Fig. 3. Uria aalge. Typical dive profile for a common murre from Funk Island, 25 to 26 July 2007, through day (unshaded), twilight (light grey) and night (dark grey). Dashed lines: periods when the bird was brooding its chick at the colony 
$\mathrm{p}=0.708$; dusk: $\left.F_{1,10}=1.15, \mathrm{p}=0.308\right)$ or for sex (dawn: $F_{1,9}=0.047, \mathrm{p}=0.833$; dusk: $\left.F_{1,10}=0.219, \mathrm{p}=0.650\right) ;$ these factors were therefore removed from the model. Analyzing the trends alone, we found that dive depths
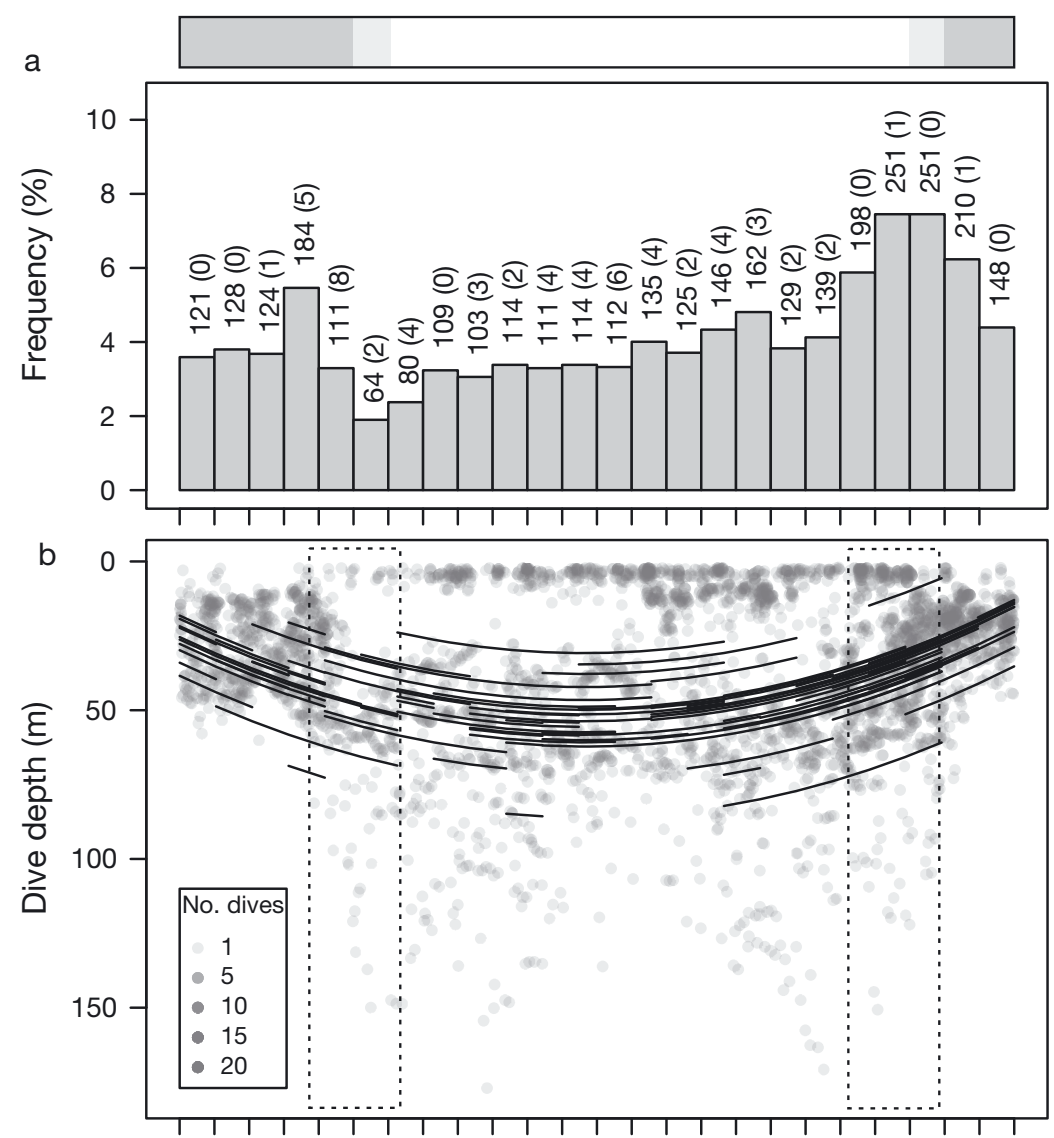

00:00 02:00 04:00 06:00 08:00 10:00 12:00 14:00 16:00 18:00 20:00 22:00 00:00 Time (local)
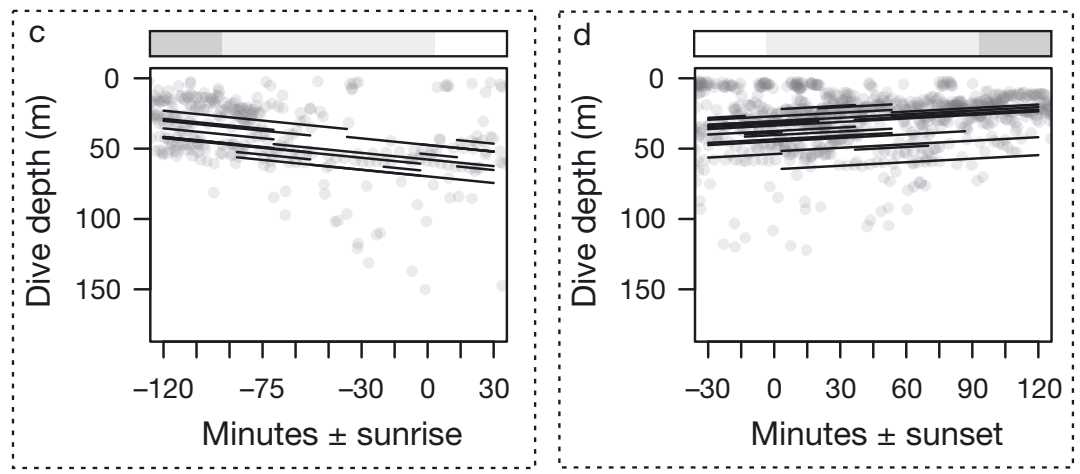

Fig. 4. Uria aalge. (a) Frequency distributions of the timing of dives indicating sample sizes and the number of terminal dives in parentheses. (b-d) Density scatterplots of dive depth through (b) the $24 \mathrm{~h}$ cycle, (c) dawn and (d) dusk for common murres foraging from Funk Island during the chick-rearing periods, July 2007 and 2008. Boxes above panels (a), (c), and (d): day (unshaded), twilight (light grey) and night (dark grey). Lines: fitted values by individual and date from linear mixed models increased through dawn $\left[F_{1,72}=9.13, \mathrm{p}=0.003\right.$; ean maximum dive depth $=55.33(45.86,64.81)+$ rate, significantly decreased through dusk $\left[F_{1,105}=\right.$ 4.38, $\mathrm{p}=0.039$; mean maximum dive depth $=36.93(29.25,44.61)-0.093$

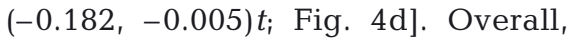
birds dove most frequently during dusk and just prior to dawn (Fig. 4a,b). While diving activity was rapidly curtailed through dawn (Fig. 4c), it was at the beginning of dawn when most terminal (presumed chick-feeding) dives were recorded (Fig. 4a). There were no differences in this pattern between sexes; however, there was no peak in diving activity during dawn in 2007 (see Fig. 4a in Hedd et al. 2009). The peak in overall dawn activity during 2008 was not resolved because the heightened activity observed in 3 individuals was outweighed by the lack of data at-sea for the other 4 individuals; they remained at the colony through dawn. The sample is more balanced with all individuals included.

\section{Diel associations between murres and capelin}

At an hourly scale, the diving activities of murres closely matched the vertical distribution of capelin (Fig. 5a). During the day, $43 \%$ of murre dives were deep and $57 \%$ shallow. Comparing this to capelin, $82 \%$ of the biomass was in deep water during the day while just $18 \%$ was in shallow water. At night, murre diving activity was primarily concentrated at depths $<50 \mathrm{~m}$ $(94 \%)$, where most of the capelin biomass was found $(86 \%)$. On a finer temporal scale during dawn and dusk periods, murre diving patterns generally matched the vertical movements of capelin. As the sun rises, deep dives of murres gradually increase as capelin move deeper in the water column (Fig. 5b), whereas dives become shallower as capelin move toward the surface as the sun sets (Fig. 5c). Slight mismatch in timing is apparent however during both twilight periods (Fig. 5b,c), which we attribute to the 

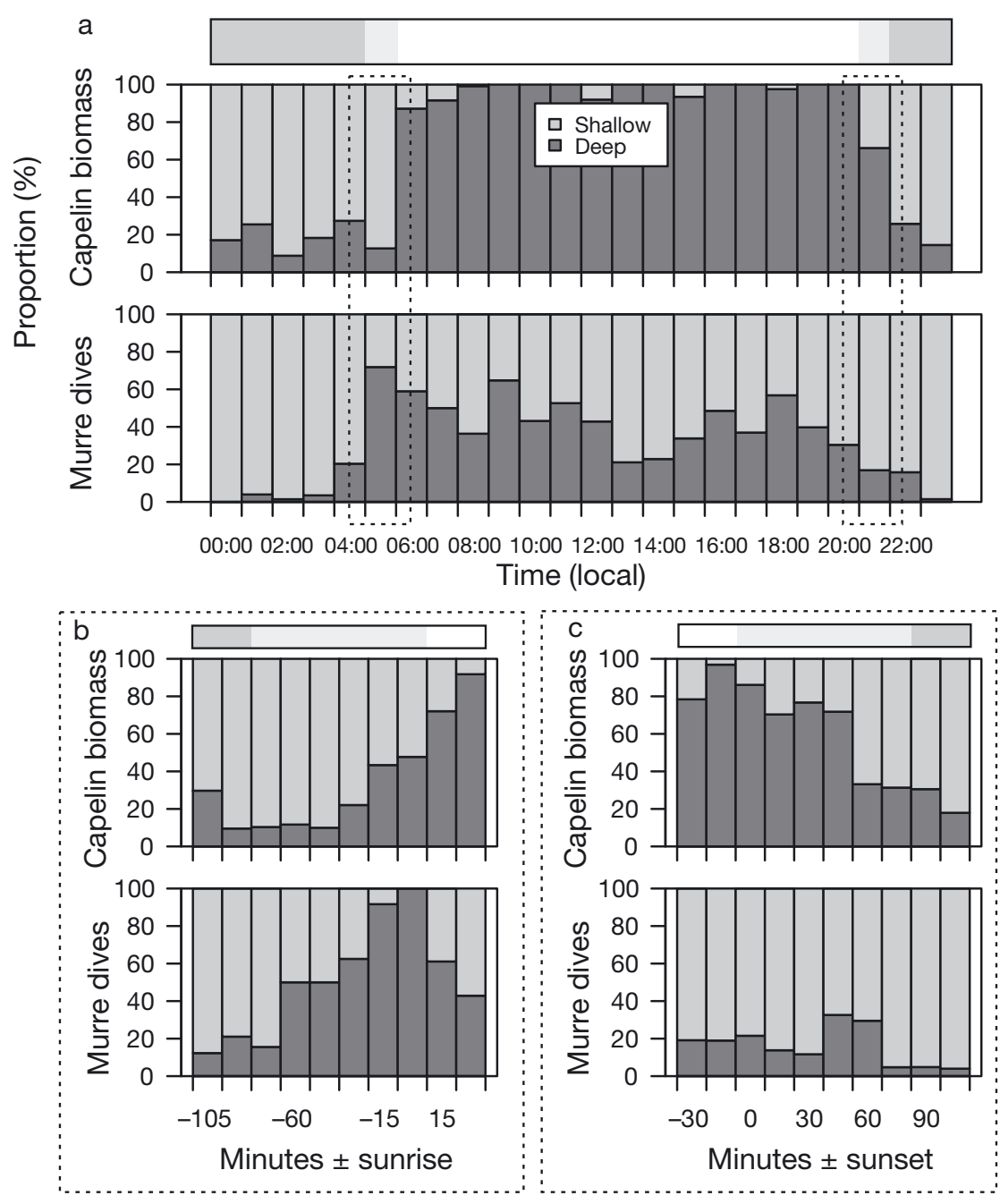

Fig. 5. Proportion of shallow $(<50 \mathrm{~m})$ and deep ( $\geq 50 \mathrm{~m})$ dives by murres in relation to percent biomass of capelin (a) by hour and at 15 min intervals through (b) dawn and (c) dusk. Boxes above panels: see Fig. 4 limitations. The question is how do both species optimize foraging under such constraints? Furthermore, what are the consequences of such tradeoffs?

Considering limitations imposed by light levels and underwater foraging costs, the murres studied here exhibited an ability to follow the vertical movements of capelin. Owing to the necessity to access capelin to sustain themselves and feed their offspring at the colony (Montevecchi 2000, Davoren \& Montevecchi 2003), their diving activities largely reflect the distribution of accessible capelin through the day, night and twilight. During daylight hours, murres frequently made deep dives to pursue capelin in cold water with low light levels. At night, murres dove in the dark, foraging on capelin at shallow depths. Tighter associations were apparent during twilight periods when the birds executed the fine-scale spatial and temporal changes in diving depths required to capture migrating capelin. Such behavioural flexibility is needed to maximize overlap with capelin undertaking broad-scale vertical movements (Davoren et al. 2007).

For diving birds foraging primarily on DVM prey, foraging opportunities may be the best during twilight periods because prey are accessible near the surface when light intensities are high enough to allow prey detection and capture (e.g. great crested grebes foraging on smelt, Piersma et al. 1988; temporal mismatch in data collection; the observed diving pattern represents active chasing of migrating capelin in a different space and time. We, therefore, do not further assess this apparent mismatch.

\section{DISCUSSION}

Predator-prey interactions span trophic levels and occur over multiple spatial and temporal scales (Hunt \& Schneider 1987). In the present study, we show that DVM by a forage fish is a pervasive phenomenon, having a cascading effect on the spatial and temporal distribution of an apex seabird predator. The vertical distributions of both capelin and murres are influenced by multiple biophysical factors, each incurring unique emperor penguins feeding on Antarctic krill, Zimmer et al. 2008). Murres performed most dives at dusk when capelin were migrating toward the surface. Few terminal dives were observed during dusk; thus, the birds appear to be concentrating on self-feeding efforts at a time when prey are most accessible and detectable. Furthermore, dusk is the last chance in the day to 'easily' capture prey, as low night-time light levels likely compromise foraging success (Wilson et al. 1993, Bost et al. 2002, Zimmer et al. 2008, Hedd et al. 2009). Moving into dawn, the birds again increase diving activity. As the sun rises, capelin migrate down the water column, increasing underwater commuting costs for murres as they have to pursue the fish toward the bottom. Focusing foraging activity at the start of dawn may therefore be the most effective strategy. The 
birds studied here did exactly that and, based on the large number of terminal dives, appeared to be taking this opportunity to capture prey for their chicks. Indeed, previous research has shown that chick provisioning rates by murres are highest around dawn (Burger \& Piatt 1990). Though the energetic requirements of chicks after a night fasting may necessitate early morning foraging efforts, the behaviour of capelin likely facilitates prey capture and delivery. In short, the presumed higher prey accessibility during dawn and dusk appear to be used as opportunities for chick and self- feeding, respectively. Such crepuscular activity likely helps maximize prey intake and chick provisioning rates.

Though capelin along Newfoundland's northeast coast are located below the CIL during the day (Davoren et al. 2006), parental murres are capable of diving deep to access them (Hedd et al. 2009). They frequently make deep dives through the day, though they made more shallow dives than would be expected given the distribution of capelin in the water column. Many shallow dives however may represent foraging efforts in shallow coastal water (Fig. 1). Indeed, murres aggregate and forage at off-beach spawning sites of capelin in shallow coastal water (Davoren 2007). Foraging efficiency is presumed to be higher in these areas due to reduced underwater commuting costs and high light availability, but this benefit comes at the costs of flying $\sim 60 \mathrm{~km}$ to the coast-this is no cheap venture as murres experience very high wing loading (2.06 $\mathrm{g} \mathrm{cm}^{-2}$; Spear \& Ainley 1997). Furthermore, time constraints limit the distance to which parental seabirds can forage from the colony (Ichii et al. 2007). If the birds decide to minimize flight time and forage in areas with deep bathymetries near the colony, they may decide to forage on the low proportion of capelin that remain near the surface. Nevertheless, nearly half of murre dives take them into deep waters to access shoals of capelin at depth. Regardless of higher underwater commuting costs, it may be profitable for murres to dive deep as capelin are more abundant and are more concentrated in distinct shoals at deeper depths during the day (Davoren et al. 2006). Furthermore, murres may be better able to capture capelin when hunting at depth because the sub- $0^{\circ} \mathrm{C}$ waters of the CIL compromise the burst/escape speeds and recovery times of fishes (Hedd et al. 2009). Murres continue toforage at night when capelin are near the surface. Hedd et al. (2009) showed that common murres experience decreased foraging efficiency at night (indicated by an increase in the number of dives per bout). This is thought to be a consequence of both a reduction in light levels and an increase in the ability of capelin to escape foraging murres in warmer surface waters.
Similar diurnal patterns in diving depths and frequency have been documented for common murres foraging in other low-latitude areas (Monterey Bay, California, $36^{\circ} \mathrm{N}$, Nevins 2004; Isle of May, Scotland, $56^{\circ} \mathrm{N}$, Thaxter et al. 2009); however, at higher latitudes, such patterns are not observed (Hornøya, Norway, $70^{\circ} \mathrm{N}$, Tremblay et al. 2003). This dichotomy has also been found in the diving behaviour of closely related thick-billed murres (cf. Croll et al. 1992, Falk et al. 2000, Mehlum et al. 2001, Jones et al. 2002). Diel diving rhythms are presumed to be related to diel migrations of local prey. The lack of such rhythms suggests that prey do not undergo DVM during permanent daylight; however, this has yet to be confirmed with congruent studies of prey behaviour.

It is important to consider that capelin too forage on DVM prey (Davoren et al. 2007). This means that the diel patterns observed in murres are ultimately driven by the diel movements of the zooplankton which capelin rely on and follow. Thus, the ecological consequences of DVM act not only over multiple spatial and temporal scales but also across trophic levels. Deviations from the typical diel pattern in capelin and murres may be explained by the various trade-offs involved in pursuing prey, avoiding predators and acting within the tolerances of behavioural and physiological limits. For a seabird that can fly and dive, common murres have exceptional diving capabilities (Piatt \& Nettleship 1985, Burger 1991, Hedd et al. 2009); however, they are ultimately limited by maximum diving depth and visual acuity. The maximum depth recorded for a common murre via TDRs is $177 \mathrm{~m}$ (present study). Capelin migrate to depths of $300 \mathrm{~m}$ (Davoren et al. 2007) and further in deeper water (Mowbray 2002). Thus, depending on the bathymetry of an area, capelin can be inaccessible to diving murres during the day. The study area near Funk Island has a gradually sloping and variable bathymetry, decreasing in depth toward the coastline (Fig. 1). Murres breeding on Funk Island forage on shoaling capelin in persistent patches in a range of bathymetries from the colony to the coast (Davoren et al. 2003a,b, 2006, Davoren 2007), which tend to be $<200 \mathrm{~m}$. It is a costly flight for the pursuitdiving murres, adding the trade-off of flight time and required diving effort, whereby birds may decide to forage near the colony in deeper waters or to fly closer to the coast and forage on capelin in shallower water. Commuting costs are much less of an issue for capelin, but unlike murres, capelin have the added factor of predation risk to contend with. Capelin therefore have to adjust their DVM pattern to optimize foraging while minimizing predation risk by northern cod (Mowbray 2002, Davoren et al. 2007). Indeed, deep cold water and warm surface water can act as refugia from predation by cod, their main historical predator, because the 
inhabited temperatures are outside the range typically occupied by cod (Rose \& Leggett 1989, Mowbray 2002). Though capelin can find refuge from cod, the diving capabilities and visual acuity of murres allow them to exploit these fish in deep, dark and cold waters by day and in dark, shallow waters by night.

Until recently it has been difficult to assess associations between the diel vertical movements of predators and prey. This is due primarily to the difficulty in conjointly tracking apex marine predators and their prey. Improvements in technology, however, allow for the investigation of such predator-prey interactions in more detail (Hays 2003). Combining diving data from murres with hydro-acoustic data on capelin allowed for detailed comparisons of DVM patterns. Associations are resolvable even though the murre and capelin data were collected in different years and different, though nearby, areas. The differences in murre diving and capelin distribution may be in part related to spatial and temporal mismatch, but we suspect they are largely due to the trade-offs faced by foraging murres. Considering the trade-offs, it is clear that murres have adapted their behaviour to exploit vertically migrating capelin. Co-evolution continues. We speculate that predation pressure from marine birds, fish and mammals - major consumers of capelin (Bundy et al. 2000) - may be selective forcers favouring the vertical migration of capelin in the northwest Atlantic. DVM is one of the most widespread and pervasive movements of animals in the world (Hays 2003). Insight regarding its ecological consequences could aid in predicting the influences of potential DVM disruptions forced by ocean climate change (e.g. Mowbray 2002). Murres exhibit great potential to act as indicators of such disruptions owing to their sensitivity to changes in the vertical distribution of capelin.

Acknowledgements. We thank A. Buren, C. Burke, F. Mowbray and G. Robertson for discussion and helpful comments. Thanks to J. Anderson, C. Burke, E. Dalley, D. Davis, N. Laite, C. Lang, E. MacDonald, P. Mallum, C. May, F. Mowbray, G. Redmond, N. White and the captain and crew of the CCGS 'Wilfred Templeman' for assistance with field work. P.M.R. benefited from the following: NSERC postgraduate scholarship, George Weston Graduate Scholarship, Leslie TuckAvian Ecology Award, and Maritime Awards Society of Canada (MASC) Maritime Studies Scholarship. This research was supported by the following grants: NSERC Strategic Grant and Fisheries and Oceans Canada provided funding for work aboard the CCGS 'Wilfred Templeman' (G.K.D., W.A.M.), NSERC Discovery Grants (G.K.D., W.A.M.), Murre Fund of the Newfoundland and Labrador Legacy Nature Trust (W.A.M.), and the Government of Canada's Program for International Polar Year (W.A.M., G.K.D.). Research on Funk Island Seabird Ecological Reserve was permitted by the Newfoundland and Labrador Parks Division. We extend a special thanks to Captain L. Easton and family for safely commuting us to and from Funk Island.

\section{LITERATURE CITED}

Bost CA, Zorn T, Le Maho Y, Duhamel G (2002) Feeding of diving predators and diel vertical migration of prey: King penguins' diet versus trawl sampling at Kerguelen Islands. Mar Ecol Prog Ser 227:51-61

Bundy A, Lilly GR, Shelton PA (2000) A mass balance model of the Newfoundland-Labrador shelf. Can Tech Rep Fish Aquat Sci 2310:i-xiv

Burger AE (1991) Maximum diving depths and underwater foraging in alcids and penguins. In: Montevecchi WA, Gaston AJ (eds) Studies of high latitude seabirds. 1. Behavioural, energetic and oceanographic aspects of seabird feeding ecology. Can Wildl Serv Occas Pap 68: 9-15

Burger AE, Piatt JF (1990) Flexible time budgets in breeding common murres: buffers against variable prey abundance. Stud Avian Biol 14:71-83

Burke CM, Montevecchi WA (2009) The foraging decisions of a central place foraging seabird in response to fluctuations in local prey conditions. J Zool (Lond) 278:354-361

Chardine JW, Robertson GJ, Ryan PC, Turner B (2003) Abundance and distribution of common murres breeding at Funk Island, Newfoundland in 1972 and 2000. Can Wildl Serv Techl Rep Ser 404

Croll DA, Gaston AJ, Burger AE, Konnoff D (1992) Foraging behavior and physiological adaptation for diving in thickbilled murres. Ecology 73:344-356

Croxall JP, Everson J, Kooyman GL, Ricketts C, Davis RW (1985) Fur seal diving behaviour in relation to vertical distribution of krill. J Anim Ecol 54:1-8

> Davoren GK (2007) Effects of gill-net fishing on marine birds in a biological hotspot in the Northwest Atlantic. Conserv Biol 21:1032-1045

Davoren GK, Montevecchi WA (2003) Signals from seabirds indicate changing biology of capelin stocks. Mar Ecol Prog Ser 258:253-261

Davoren GK, Montevecchi WA, Anderson JT (2003a) The influence of fish behaviour on search strategies of common murres Uria aalge in the Northwest Atlantic. Mar Ornithol 31:123-131

Davoren GK, Montevecchi WA, Anderson JT (2003b) Search strategies of a pursuit-diving marine bird and the persistence of prey patches. Ecol Monogr 73:463-481

> Davoren GK, Anderson JT, Montevecchi WA (2006) Shoal behaviour and maturity relations of spawning capelin (Mallotus villosus) off Newfoundland: demersal spawning and diel vertical movement patterns. Can J Fish Aquat Sci 63:268-284

> Davoren GK, May C, Penton P, Reinfort B and others (2007) An ecosystem-based research program for capelin (Mallotus villosus) in the Northwest Atlantic: overview and results. J Northw Atl Fish Sci 39:35-48

> Davoren GK, Garthe S, Montevecchi WA, Benvenuti S (2010) Influence of prey behaviour and other predators on the foraging activities of a marine avian predator in a Low Arctic ecosystem. Mar Ecol Prog Ser 404:275-287

Elliott KH, Woo K, Gaston AJ, Benvenuti S, Dall'Antonia L, Davoren GK (2008) Seabird foraging behaviour indicates prey type. Mar Ecol Prog Ser 354:289-303

Falk K, Benvenuti S, Dall'Antonia L, Kampp K, Ribolini A (2000) Time allocation and foraging behaviour of chickrearing Brunnich's guillemots Uria lomvia in high-arctic Greenland. Ibis 142:82-92

Fridolfsson A, Ellegren H (1999) A simple and universal method for molecular sexing of non-ratite birds. J Avian Biol 30:116-121 
Hays GC (2003) A review of the adaptive significance and ecosystem consequences of zooplankton diel vertical migrations. Hydrobiologia 503:163-170

Hedd A, Regular PM, Montevecchi WA, Buren AD, Burke CM, Fifield DA (2009) Going deep: common murres dive into frigid water for aggregated, persistent and slowmoving capelin. Mar Biol 156:741-751

Hunt GL, Schneider DC (1987) Scale-dependent processes in the physical and biological environment of marine birds. In: Croxall JP (ed) Seabirds feeding ecology and role in marine ecosystems. Cambridge University Press, Cambridge, p 7-41

Ichii T, Bengtson JL, Boveng PL, Takao Y and others (2007) Provisioning strategies of Antarctic fur seals and chinstrap penguins produce different responses to distribution of common prey and habitat. Mar Ecol Prog Ser 344:277-297

Jones IL, Rowe S, Carr SM, Fraser G, Taylor P (2002) Different patterns of parental effort during chick-rearing by female and male thick-billed murres (Uria lomvia) at a low-arctic colony. Auk 119:1064-1074

Lavigne DM (1996) Ecological interactions between marine mammals, commercial fisheries, and their prey: unravelling the tangled web. In: Montevecchi WA (ed) Highlatitude seabirds. 4. Trophic relationships and energetics of endotherms in cold ocean systems. Can Wildl Serv Occas Pap 91, Canadian Wildlife Services, Ottawa, ON, p 59-71

Lawson GL, Rose GA (1999) The importance of detectability to acoustic surveys of semi-demersal fish. ICES J Mar Sci 56:370-380

Levy DA (1990) Reciprocal diel vertical migration behavior in planktivores and zooplankton in British Columbia lakes. Can J Fish Aquat Sci 47:1755-1764

MacLennan DN, Fernandes PG, Dalen J (2002) A consistent approach to definitions and symbols in fisheries acoustics. ICES J Mar Sci 59:365-369

Mehlum F, Watanuki Y, Takahashi A (2001) Diving behaviour and foraging habitats of Brunnich's guillemots (Uria lomvia) breeding in the high-arctic. J Zool (Lond) 255: 413-423

Montevecchi WA (2000) A mass balance model of the Newfoundland-Labrador shelf. In: Bundy A, Lilly GR, Shelton PA (eds) Seabirds. Can Tech Rep Fish Aquat Sci 2310, St. John's, Newfoundland, p 15-18

Montevecchi WA, Tuck LM (1987) Newfoundland birds: exploitation, study, conservation. Nuttall Ornithological Club, Cambridge, MA

Mowbray FK (2002) Changes in the vertical distribution of capelin (Mallotus villosus) off Newfoundland. ICES J Mar Sci 59:942-949

Nevins HM (2004) Diet, demography, and diving behaviour of the common murre (Uria aalge) in central California. MSc thesis, San Francisco State University, CA

Orians GH, Pearson NE (1979) On the theory of central place foraging. In: Horn DJ, Stairs GR, Mitchell RD (eds) Ana-

Editorial responsibility: Yves Cherel, Villiers-en-Bois, France lysis of ecological systems. Ohio State University Press, Columbus, OH, p 155-177

Petrie B, Akenhead SA, Lazier SA, Loder J (1988) The cold intermediate layer on the Labrador and northeast Newfoundland shelves, 1978-86. NAFO Sci Counc Stud 12: 57-69

Piatt JF, Nettleship DN (1985) Diving depths of four alcids. Auk 102:293-297

Piersma T, Lindeboom R, Van Eerden MR (1988) Foraging rhythm of great created grebes Podiceps cristatus adjusted to diel variations in the vertical distribution of their prey Osmerus eperlanus in a shallow eutrophic lake in the Netherlands. Oecologia 76:481-486

R Development Core Team (2008) R: a language and environment for statistical computing. R Foundation for Statistical Computing, ISSN/ISBN 3-900051-07-0, available at www. r-project.org

Rose GA, Leggett WC (1989) Interactive effects of geophysically-forced sea temperatures and prey abundance on mesoscale coastal distributions of a marine predator, Atlantic cod (Gadus morhua). Can J Fish Aquat Sci 46: 1904-1913

> Shepard ELC, Ahmed MZ, Southall EJ, Witt MJ, Metcalfe JD, Sims DW (2006) Diel and tidal rhythms in diving behaviour of pelagic sharks identified by signal processing of archival tagging data. Mar Ecol Prog Ser 328:205-213

> Spear LB, Ainley DG (1997) Flight behaviour of seabirds in relation to wind direction and wing morphology. Ibis 139: 221-233

> Tarling GA, Matthews JBL, David P, Guerin O, Buchholz F (2001) The swarm dynamics of northern krill (Meganyctiphanes norvegica) and pteropods (Cavolinia inflexa) during vertical migration in the Ligurian Sea observed by an acoustic Doppler current profiler. Deep-Sea Res I 48: 1671-1686

> Thaxter CB, Daunt F, Hamer KC, Watanuki Y and others (2009) Sex-specific food provisioning in a monomorphic seabird, the common guillemot Uria aalge: nest defence, foraging efficiency or parental effort? J Avian Biol 40: $75-84$

> Tremblay Y, Cherel Y, Oremus M, Tveraa T, Chastel O (2003) Unconventional ventral attachment of time-depth recorders as a new method for investigating time budget and diving behaviour of seabirds. J Exp Biol 206:1929-1940

Wilson RP, Puetz K, Bost CA, Culik BM, Bannasch R, Reins T, Adelung D (1993) Diel dive depth in penguins in relation to diel vertical migration of prey: whose dinner by candlelight? Mar Ecol Prog Ser 94:101-104

Zaret TM, Suffern JS (1976) Vertical migration in zooplankton as a predator avoidance mechanism. Limnol Oceanogr 21: $804-813$

Zimmer I, Wilson RP, Beaulieu M, Ancel A, Ploetz J (2008) Seeing the light: depth and time restrictions in the foraging capacity of emperor penguins at Pointe Geologie, Antarctica. Aquat Biol 3:217-226

Submitted: February 3, 2010; Accepted: July 28, 2010

Proofs received from author(s): September 12, 2010 